\title{
oral contraceptive use was associated with myocardial infarction and ischaemic stroke but not angina
}

Want], Painter R, Vessey M. Risk of nocardial infarction, angina and stoke in users of oral contraceptipes: an updated analysis of a cohort study. Br J Obstet Gynaecol. 1998 Aug; 105:890-6.

\section{question}

In women who take oral contraceptives $(O C s)$, is the risk for cardiovascular disedse increased?

\section{Design}

Cohort study with up to 26 years of follow-up.

\section{Setting}

17 family planning clinics in England and Scotland.

\section{Participants}

17032 women who attended a family planning clinic between 1968 and 1974. Women were included if they were martied, Caucasian, had British citizenship, and were between 25 and 39 years of age. The participants were sent annual questionnaires that requested information on method of contraception, past medical history, social history, and height and weight. 15292 women $(90 \%)$ were still participating at age 45 , at which time they were sent a questionnaire that also requested information on smoking status.

\section{Assessment of risk factors}

At age 45, women were categorised as never-users of the OC pill $(n=5881)$, users of the $O C$ pill for $>8$ years $(n=$ 3520 ), or users for $\leq 8$ years $(n=5891)$.

\section{Main outcome measures}

Myocardial infarction (MD), angina, ischaemic stroke, subarachnoid haemorrhage, intracerebral haemorthage, and transient ischaemic attack. The event rates were adjusted for age, social class, smoking, and obesity (all diagnoses) and for parity (MI and angina). A restricted analysis was done excluding women with hypertension, diabetes, or hyperlipidaemia.

\section{Main results}

No association between $O C$ use and $M I$ was seen in the whole study population. When women with hypertension, hyperlipidaemia, or diabetes were excluded (restricted analysis), an increased risk for MI existed among women who used OCs for up to 8 years (relative risk [RR] $1.9,95 \%$ CI 1.0 to 3.5 ). In further analyses, this risk was seen only in heavy smokers $(\geq 15$ cigarettes/d): In heavy smokers, the RR for $M I$ in ever-users of OCs was 4.2 (CI 1.4 to 16.6 ), or for every 1060 heavy smokers taking $O C s$, 1 addicional $M V / y$ occurred. Risk for angina was generaily similar in $\mathrm{OC}$ users and never-users. Risk for ischaemic stroke was increased in current users. After adjustment for age, social class, smoking, and obesity, the RR was 2.4 (CI 1.1 to 5.1); the adjusted RR after restriction was 2.9 (CI 1.3 to 6.7) (1 additional stroke/y for every 5880 OC users).

\section{Conclusions}

Oral contraceptive use was associated with an increased risk for myocardial infarction in heavy smokers. Current use was associated with a small increase in the risk for ischaemic stroke.

Sources of funding: Medical Reseanch Council and Knot Family Thus.

For correspondence: Di: 7. Mant, Department of General Practice, The Medical School, Edgbaston, Bimminghant B15 2TT, England, UK. FAX 44-121-414-6571.

\section{Commentary}

Stroke and MI are tare events among women of reproductive age. Prospective examination of the effects of $O C$ s on these outcomes reguires large cohorts and long follow-up time. Women already known to be at risk for stroke or MI are unlikely to be prescribed $O C s$, which makes defnition of $O C$ effects on women with risk factors for ardiovascular disease difficult. The progressive decrease in OC estrogen dose over the past 30 years complicates the application of results from older studies to women asing the current low-dose-estrogen $\mathrm{OCs}$.

The study by Mant and colleagues that updates the Oxford Family Planning Association study is one of several recent reports tevisiting the cardiovascular effects of $O \mathrm{Cs}$ (1-4). This study, with over 20 years of follow-up and over 300000 woman-years of observation, is well suited for rare events. It is not much help with understanding the effects of current low-dose estrogen $O \mathrm{Cs}$ because $68 \%$ of the woman-years of exposure are from $O C$ containing $50 \mu \mathrm{g}$ of estrogen. It can, however, serve with other reports to establish a benchmark for the worst cardiovascular effects of $O \mathrm{Cs}$ in healthy women. Another zecent study suggests that lower-dose OCs may noc increase risk for MI, even among smokers (3), although low-dose OC nsers who smoke are at increased risk for stroke (4).

The findings of these studies and others are reassuring to women wishing to use $O C s$ and to their clinicians. For nonsmokers with normal blood pressure, the risk for $M I$ is not affected by $O C$ use. Increased risk for MI is confined to women smoking $\geq 15$ cigarettes per day. Risk for stroke is minimally increased among current $O C$ users. In contrast, the health risks of smoking are enormous. Clinicians need to help patients quitsmoking and to work together for public health regulations that make it harder for young people to start.

Foy Melnikow, MD, MPH University of California, Davis Sacramento, Califonia, USA

\section{References}

1. World Health Organ Tech Rep Ser. 1998; 877:i-vii, 1-89.

2. Heinemana LA, Lewis MA, Thorogood $M$, et al. BMJ. 1997;315:1502-4.

3. Sidney $S$, Siscovick DS, Petitti DB, et al. Circulation. 1998;98:1058-63.

4. Petitti DB, Sidney $S$, Berustein A, et al. N Engl] Mef. 1996;335:8-15. 